\title{
THE PROFESSIONAL TRANSLATOR AND INFORMATION LITERACY: PERCEPTIONS AND NEEDS
}

\author{
Dora Sales (University Jaume I) \\ Department of Translation and Communication, Avda. Sos Baynat, s/n, 12071, \\ Castellón, Spain \\ e-mail: dsales@trad.uji.es
}

Dora Sales is Senior Lecturer in Documentation at the University Jaume I of Castellón, Spain. Her main research interests are Documentation applied to Translation Studies and intercultural communication. She is heading researcher in funded R\&D projects in the field of Documentation for intercultural communication and mediation. She is a practising literary translator.

María Pinto (University of Granada) Department of Information Science, P o de Cartuja, s/n, 18071, Granada, Spain, email: mpinto@ugr.es

Maria Pinto is Professor of Information Science at the University of Granada, Spain. She is an expert in the field of abstracting, knowledge representation and data quality management. Also, she is the heading researcher of diverse R\&D projects on abstracting and e-learning portals in the context of information literacy.

\section{Abstract}

This paper is part of a broader research project, the main goal of which is to provide translators with solid instruction in Information Literacy (IL). For this, it is important to know the views of the community of professional translators. The results of the ongoing research which we analyze in this paper provide this view, by means of a qualitative case study (using a semi-structured questionnaire for data gathering). These results highlight the strengths and weaknesses indicated by professional translators regarding the information competences they need.

Key words: Information Literacy, INFOLITRANS survey, professional translators, empirical study, case study. 


\section{INTRODUCTION}

The INFOLITRANS (INFOrmation LIteracy for TRANSlators) survey, designed to detect information literacy (IL) training needs, has been successfully used among students and faculty in the field of translation and interpretation. We now apply the survey to a sample of professional translators in order to uncover their perceptions and needs with a view to improving aspects of professional training, by examining the levels of importance and success they attribute to each of the survey's 20 closed items, and their responses to 6 open questions.

The main aim of the research described in this paper is to gather empirical data in order to develop a framework for implementing, in a near future, a program designed to meet the needs of a specific user group, namely translation and interpretation professionals. In this sphere of application, it is important to remember that translators are not only information users, but also information processors and producers. Translation is, above all, a specialist activity that demands a constant flow of information. Translators are faced with the challenge and the responsibility of becoming acquainted with and using the diverse means that now exist for the location, retrieval, handling and dissemination of information, and of manipulating the extraordinary new resources that information and telecommunications technologies have made available for their work.

In today's rapidly changing environment, the translator faces new situations that have emerged from the exponential growth of technologies and the flood of documentary and information material that has arrived in their wake. An awareness of professionals' opinions is vital if we are to successfully put into practice actions for improvement. In this essential quest for direct, current perceptions, the INFOLITRANS survey has enabled us to 
increase and improve our knowledge of the real situation facing the professional translator today, and the needs of this community.

\section{BACKGROUND}

As we have stated in the introduction, this paper is part of a larger research project, in which our aim is to establish and diagnose the state of development of information skills in the context of translation, from a user-centred perspective taking in three groups: 1 . students (Pinto \& Sales, 2007), 2. teachers and academics (Pinto \& Sales, 2008a), and 3. professionals, in this paper.

We believe that this work is pioneering and innovative in its field, aiming as it does to offer data based on the evidence provided by experts, which enables us to accumulate significant information with a view to proposing integrated training strategies, both in class and virtually, that can offer multiple outlets for students and professionals to learn and practice information literacy skills.

In an innovative move for its time, Spanish authorities, at the suggestion of early translator trainers in Spain, included a minimum of forty class-contact hours in "documentary research applied to translation" as a core course component, when the full undergraduate degree course in translation was introduced in Spain in 1991. Teachers specializing in translation are acutely aware of the importance of documentation in their professional activity and of their responsibility to teach students how to document themselves in order to translate in a responsible and effective fashion (Hatim \& Mason, 1990). Those who teach documentary research in a number of universities (who may not be practicing translators) are aware that what they have to convey to their students consists of skills for training in information competences, so that they can learn to manage, analyze, summarize, 
synthesize, access, locate, evaluate, store, optimize and share information in order to create knowledge. In addition, in its white paper on the degree course in translation in the framework of adaptation to the European Higher Education Area (ANECA, 2004), the Spanish National Agency for Quality Evaluation and Accreditation (ANECA) has stressed the need for graduates to be trained in strategic and technological information management, as well as to acquire the skills required in order to seek and evaluate information irrespective of medium.

We thus see that information competence is essential for the practice of translation and is therefore highly valued in the training of students of translation. Documentation skills offer the translator a systematic working method and a structured knowledge system, criteria for selecting and evaluating information, and techniques for organizing, storing and retrieving it (Pinto, 2001).

\section{LITERATURE REVIEW}

It is well-known by now that information literacy entails the learning of the skills, competencies, knowledge and values to access, use and communicate information in any of its forms, in order to produce competent students and professionals trained in the routines of identifying, evaluating and recording information sources appropriately and with the knowledge to process and produce their own information. Today, IL is inextricably associated with information practices and critical thinking in the information and communication technology environment.

Therefore, information literacy instruction, in addition to the lower-order skills, includes higher-order abilities such as: assessing search results for quality and relevance; evaluating the reliability, validity, authority, and timeliness of retrieved information; and applying new 
information to the planning and creation of scholarly and professional pursuits (Maugham, 2001).

In broad terms, information literacy is the set of literacies or competencies that an informed citizen needs in order to participate judiciously and actively in an information society. Information literacy is vital for the modern information-intensive world, enabling personal, economic, social and cultural development (Corrall, 2007). Yet literacy means competence. Though there are other more holistic views of competence prevailing in the higher education community (Barnett, 1997; Sandberg, 2000) the present research is restricted to a rationalistic view focused on worker competence (knowledge, skills and abilities).

All in all, the theoretical framework of this study places us, on the one hand, in the field of user-focused studies, from the area of the diagnosis of needs, and, on the other, in the context of the Information Literacy educational approach. In fact, we align ourselves with the following statement:

There appears to be little doubt that IL acts a catalyst for learning in formal, workplace and community settings (Lloyd, 2006). However, the dominant conceptions of IL that have emerged from library and information science research may be too narrow to accommodate the claims which have been made for IL as generic sets of skills and attributes which are pre-requisites to prepare people for lifelong learning (Bundy, 2004). (...) research emerging from the workplace and community sectors challenges the current approaches by introducing new conceptions and perspectives about IL (Lloyd and Williamson, 2008: 9).

Taking into account that this paper is part of a broader research project, we refer readers to a previous paper (Pinto \& Sales, 2007), where we already put forward our theoretical framework.

Nonetheless, we would like to recall that our research aligns itself with the approach (notably including Wilson's holistic viewpoint) which, since the 1980s, has arisen in this area of research within the field of documentation and has marked a shift from the traditional system-oriented approach, focused essentially on a user-oriented approach that is more 
concerned with users' needs. In this sense, fieldwork, for instance by means of surveys, becomes essential.

As we know, Information Literacy forms the basis for lifelong learning (UNESCO, 2005). It is common to all disciplines, to all learning environments, and to all levels of education. It enables learners to master content and extend their investigations, become more self-directed, and assume greater control over their own learning.

The concept, standards and theoretical basis of IL have received extensive attention, but there is still much work to do to bridge the gap between theory and action, proposing IL studies and training programs applied to specific communities of practice, real user groups with their own information literacy needs. Fortunately, the research in this field is growing healthily, and recent publications, such as Andretta (2007) and the first issue of the Journal of Information Literacy (2007), show that applied papers and research results are a major trend.

In this connection, we proposed the INFOLITRANS model (Pinto \& Sales, 2008b), which we conceive from an integral perspective in cascade, from the more contextual elements up to its concrete embodiment in teaching proposals: main facets, key skills, generic abilities and learning objectives for the deployment of those skills, all of the above being interrelated and integrated into the translation process.

INFOLITRANS is developed from our perspective on information processing. Our approach is multiparadigmatic, while at the same time laying major weight on the sociocognitive perspective (Zins, 2007), taking into account the nature the information itself, as a multifaceted phenomenon arising from the combination of four basic factors: substantive content (cognitive, semantic), situational content (strategic), addresser's attitude to the reality and addressee's attitude to that same reality. The efficient processing of information is based on the bidirectional analysis of both documentary content and information needs. 
All in all, the INFOLITRANS model is the result of the negotiated fusion of our integrating view of documentation based on our backgrounds, which combine knowledge in teaching information studies, experience in the area of information science applied to translation, and our experience as professional translators. It is a multi-faceted model, designed for the new virtual work environments and competence-based.

Learning to become information literate takes time. It is necessary to understand the purpose and the context of the task and to know how to use the information and communication technologies to locate and retrieve sources. We must also know how to consult them and assimilate their contents, which involves comprehension of both the concepts and the interrelations and then synthesizing and representing the information in a suitable manner in order to build up a personal knowledge bank. The translator plays a key role in the transfer process by becoming the producer of a new document that represents the source text, which is to fulfill a certain function in the target context. As a professional, the translator must have a thorough knowledge of the foreign language and be in possession of transfer competence and intercultural competence; he or she must also be information literate and have a full understanding of the subject material and the specific context of the source text, as well as knowing how to communicate its content-form within the context of a new situation. As we have said above, the translator must be trained in and capable of handling and using information in all its forms and varieties.

\section{METHODOLOGY}

Our methodological approach is triangulated, using both qualitative and quantitative techniques, although our view as a whole is qualitative. For a detailed account of our methodological basis, we again refer to Pinto \& Sales (2007), though we would like to 
enhance here the methodological triangulation of the research, which, as Patton (1987) puts forward, concerns the use of various techniques of information retrieval for user study purposes. Obviously, triangulation enables a deeper understanding of aspects of the realities observed, as well as enriching the research and making it more inclusive and reliable. In the present study, we shall make use of methodological and data triangulation as follows:

- Data triangulation: translation and interpreting professionals from diverse specializations

- Methodological triangulation: use of multiple techniques for studying the same realities (semi-structured questionnaire with both graded -quantitative- and openended -qualitative- questions).

In order to obtain data directly from the body of professional translators, we designed a questionnaire, based on our previous diagnostic experience with students and trainers.

Thus, and in order to start from a common core, the questionnaire used here (INFOLITRANS $^{\mathrm{P}}$ - professional) is very similar to the one we used for our earlier research with the students and trainers. However, the open questions section has been accordingly adapted to the professional context. The questionnaire consists of 26 items: 20 closed questions using the Likert scale (1-4) and 6 open-ended questions (for text, see Appendix). This methodological decision to use the same basic questionnaire reflects our twofold aim of obtaining a global validation of the INFOLITRANS tool as an integrated instrument for measuring the perception of levels of competence in $\mathrm{IL}$, and of building a reliable picture of the different tendencies, needs and shortcomings within this community of practice, in the context of developing a well-integrated and specific information literacy program.

To design the items of the questionnaire, we have drawn on our experience as teachers and researchers in the field of translation, and on the following specific models: INFOLITRANS (Pinto \& Sales, 2008b) and ANECA (ANECA 2004). 
Thus, we have taken into account the conclusions reached in the study promoted by the ANECA in order to propose a Degree in Translation as part of the reforms deriving from European convergence (ANECA, 2004). What we are interested in highlighting is the fact that the final report on the project suggests a number of important considerations with respect to Information Sciences in translator training. Indeed, in (almost) all the professional profiles included in the report (general professional translator, linguistic and cultural mediator, liaison interpreter, publishing reader, editor, proof-reader or reviewer, lexicographer, terminologist and linguistic project manager) the need to be trained in the (conceptual and technological) management of information and documentary material is constantly highlighted. The capacity to manage information stands out as one of the main generic core competencies. Among all the specific competencies that the report classifies as being disciplinary (knowledge), professional (know-how) or academic, emphasis is placed on the fact that one of the specific competencies required by the translator is the skill to search for information and carry out documentary research.

On the other hand, we use the INFOLITRANS model (Pinto \& Sales, 2008b), which we conceive from an integral perspective and which we present in cascade, from the more contextual elements up to its concrete embodiment in teaching proposals: main facets, key skills, generic abilities and learning objectives for the deployment of those skills, all of the above being interrelated and integrated into the translation process.

The INFOLITRANS is located in an applied context in which various factors coexist (here we draw our inspiration from Bruce, 1997), i.e.: knowledge, technologies, resources and processes. These facets require the development of a series of correlated competences and skills, namely: cognitive, informative-digital, communicative and procedural-strategic.

\section{Data collection}


The INFOLITRANS tool was installed online and housed on a server (URL: http://www.mariapinto.es/alfintra/) for the purposes of the study; the operating system used was Linux. The web server used was Apache 2.0, the server language was PHP 4.4.4, and the database system, MySQL 4.1.22.

The questionnaire (see Annex) was sent out in electronic format during October 2007 through the CCDUTI (Conferencia de Centros y Departamentos Universitarios de Traducción e Interpretación del Estado Español - Conference of Centers and University Departments of $\begin{array}{llll}\text { Translation and } & \text { Interpreting Studies }\end{array}$ (http://www.ua.es/dpto/dfing/ccduti/index.html), since most faculty working on Spanish Translation degrees are also professionals in the field. Distribution lists such as infotrad@uji.es, doctotrad@uji.es (distribution lists at the Universidad Jaume I, though they have a national scope) and lista siit@dtil.unilat.org (a distribution list on translation in Latin America) were also used.

The data gathering phase ran until April 2008, when the data treatment process began. A total of 101 questionnaires were received from all specialist areas. Based on the first specialty noted by respondents, the questionnaires were distributed as follows: scientific-technical translation (48), literary translation (13), audiovisual translation (6), legal or administrative translation (20) and interpretation (14).

The participants, thus, cover widely the diverse specialties in translation studies: scientific-technical translation, practiced by those who focus on the translation of technical and scientific texts, in diverse fields, such as engineering, medicine, computing systems, etc. Literary translation, practiced by professionals who translate literature in its different possibilities (novel, poetry, short-story, theatre...), and audiovisual translation, which is centered on the translation of films, videogames, etc. We also have informants of the 
specialty of legal and administrative translation, that is, those who translate legal documents or any type, and, finally, interpreters, who translate orally in conferences or public services, such as hospitals, courts, schools and so on.

Therefore, we consider that the sample gathered is representative and varied, taking into account that the informants come from diverse universities and specializations in the field; this is important since the objective of the INFOLITRANS tool is to obtain reliable data on professional translators' views of their training in information skills, through an analysis of two dimensions of each skill: importance and success. We understand importance to mean the value the translator places on competency in a given skill within his or her translation practice; success refers to the degree to which he or she has acquired that skill. On the basis of this study, it should be possible to carry out reliable comparative analyses with a view to identifying gaps and training needs for each of the information skills, and subsequently designing suitable and workable action and training plans or resources that can be properly applied to a given context and will strengthen instruction in documentation for professional translators.

As in the other phases of the INFOLITRANS project, we used two different techniques to process the data from the online questionnaires: quantitative for the first 20 items (descriptive statistical method using version 14 of the SPSS program), and qualitative (based on content analysis techniques) for the six open-ended questions. We believe that the combination of these two, from the perspective of methodological triangulation (Patton, 1987), which we also applied in Pinto \& Sales (2007, 2008a), yields results that are of interest for research by enabling conclusions to be drawn based on data and evidence arising from a broad analysis that, in addition, can correlate professionals' views with those of faculty and students of translation. 


\section{FINDINGS AND DISCUSSION}

In general, the overall results of the statistical-descriptive analysis are significant in terms of the average values for the dimension importance of the different skills, which, on a Likert scale (1-4), tend to register between 3 and 4. In other words, professional translators regard a large number of the skills as important or very important. On the other hand, scores for their perception of the degree of achievement of the various skills fluctuate between 2.5 and 3.4 .

The figure below presents an overview of the results obtained:

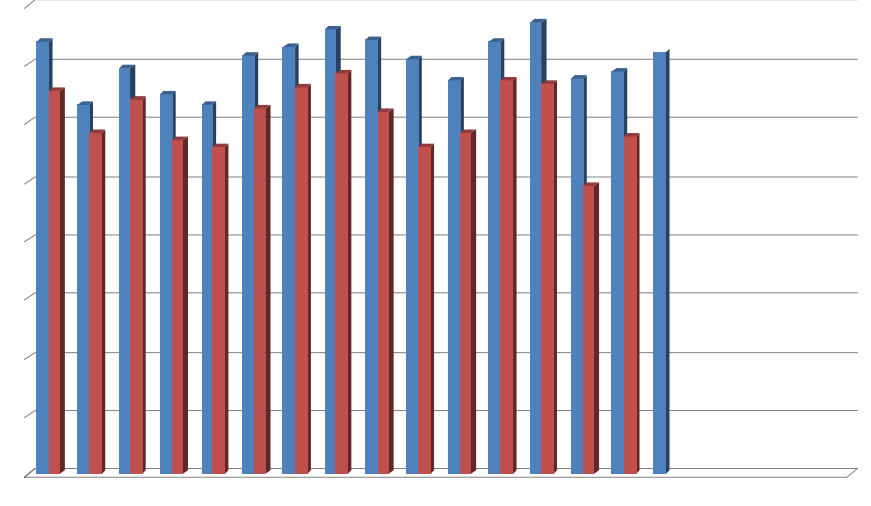

These results suggest various aspects that we consider significant:

1. The professional translators regard all the items in the questionnaire, and therefore all the skills identified, as being of major importance. The first item in order of importance is "knowing how to access specific Internet resources and retrieve specialized information accurately" (3.86). It is clear that in this professional context, in which the Internet is frequently the principal channel of information, assignment deadlines underlie the daily work of the translator. Therefore, agility, operability and precision are essential factors. 
This item was followed-in order of importance-by "knowing how to use a computer as a professional tool" (3.80), "knowing how to take decisions autonomously and efficiently" (3.78), "awareness of existing information sources that can be consulted" (3.71), "having the skills to analyze and synthesize information" (3.70) and "knowing how to use encyclopedias, dictionaries and databases to find specific information" (3.70).

All these factors again illustrate the reality facing these professionals, who must have a good command of computer skills to carry out their work, together with a well-developed capacity for taking the decisions that, in the end, pervade all translation work, and also a specialized knowledge of information sources.

Translators also place a high value on information analysis and summarizing skills, precisely because of their need for the agility and operability mentioned above. The professional translator handles huge amounts of information; training in analysis and synthesis skills is therefore important to the organization and optimization of information, particularly for interpreters (that is, those specialized in oral translation, not translation of written texts). The use of encyclopedias, dictionaries and databases to find specific information is also highly valued, in line with the other skills identified as priorities.

2. With regard to the dimension of success in acquiring the various skills, professional translators locate their highest level of success in the skill of "knowing how to use a computer as a professional tool" (3.42), precisely because the translator's workstation (computer with broadband Internet connection, scanner, e-mail, chat, etc.) is vital to his or her professional standing, autonomy and efficiency.

This item is followed closely by "knowing how to take decisions autonomously and efficiently" (3.39), which is clearly integral to the translator's task, "knowing how to use encyclopedias, dictionaries and databases to find specific information" (3.37), "knowing 
how to structure and produce well written texts" (3.30) and "having the skills to analyze and synthesize information" (3.27).

Broadly speaking, there is a correlation between the items considered to be most important and those perceived as being used successfully, with the exception of the first most highly valued item, "knowing how to access specific Internet resources and retrieve specialized information accurately", for which the perception of success is lower. This insight is particularly relevant since it reflects the professional translator's need for focused specialized training. This need may be met through an almost "à la carte" application of IL (Information Literacy), attending to the specific needs of each specialist area, and may be a highly productive and useful way of working for professional translators.

3. Also worthy of mention is the item with the lowest score in terms of success, "documentation skills for managing and reusing your information (creation of databases, terminology banks, networks, etc.)", an aspect that we believe is linked to the need for specialized training in information skills that would benefit translators' professional practice, by improving the agility and efficiency demanded by the market and work assignments, and, in short, the day-to-day reality of the profession.

It is precisely in this item, "documentation skills for managing and reusing your information (creation of databases, terminology banks, networks, etc.)", that we see the greatest difference between attributed importance (3.38) and the level of perceived success (2.46), revealing a clear need for improvement. 


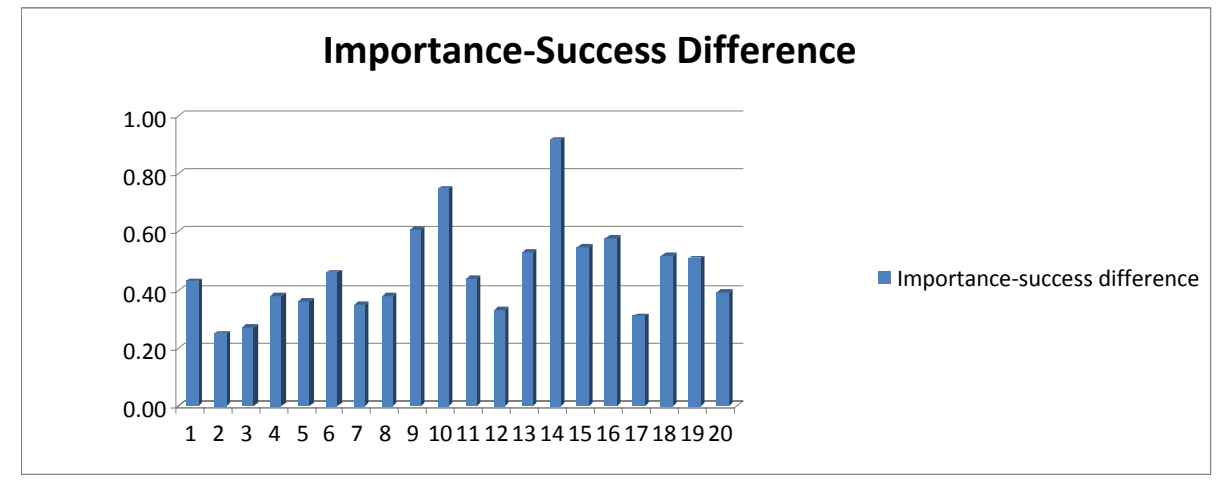

The INFOLITRANS survey enables us to diagnose and identify possible needs for resources or specific training that could help improve the day-to-day work of professional translators.

The following table reports the full results for the questions in terms of importance, level of success, and the difference between the two values:

Calculations with imputed values using the SPSS 14.0 program

Average value - importance: 3.52

Average value - success: 3.05

$\begin{array}{cccc}\text { Item } & \text { Importance } & \text { Success } & \text { Difference } \\ 1 & 3.70 & 3.27 & 0.43 \\ 2 & 3.16 & 2.91 & 0.25 \\ 3 & 3.47 & 3.20 & 0.27 \\ 4 & 3.24 & 2.86 & 0.38 \\ 5 & 3.15 & 2.79 & 0.36 \\ 6 & 3.58 & 3.12 & 0.46 \\ 7 & 3.65 & 3.30 & 0.35 \\ 8 & 3.80 & 3.42 & 0.38 \\ 9 & 3.71 & 3.10 & 0.61 \\ 10 & 3.55 & 2.80 & 0.75 \\ 11 & 3.36 & 2.92 & 0.44 \\ 12 & 3.70 & 3.37 & 0.33 \\ 13 & 3.86 & 3.33 & 0.53\end{array}$




$\begin{array}{llll}14 & 3.38 & 2.46 & 0.92 \\ 15 & 3.44 & 2.89 & 0.55 \\ 16 & 3.60 & 3.02 & 0.58 \\ 17 & 3.35 & 3.04 & 0.31 \\ 18 & 3.55 & 3.03 & 0.52 \\ 19 & 3.36 & 2.85 & 0.51 \\ 20 & 3.78 & 3.39 & 0.39\end{array}$

Table 1. Average values for importance and success

This general evaluation is followed by a cluster analysis, as previously used in our research with students and faculty (Pinto \& Sales 2007, 2008a, Sales 2008), to analyze in greater depth the groups of skills established in line with the summary presented in the previous table.

We would like to stress that the idea behind this research is that IL is grounded in a set of generic information skills, but that each community of practice may express the need for certain specific information skills, according to its own parameters and specificities. Nonetheless, for the purposes of identifying these skills, and at this present essential diagnostic stage, we consider that the diagnosis should be carried out on the basis of generic information skills. In fact, these skills are not simply generic since they have either been identified as essential by expert trainers in translation studies, within a broad framework of consensus (in the ANECA report), or else defined in the applied INFOLITRANS proposal.

Thus, the following tables offer a summary of the work clusters we have used in our research hitherto, correlating the skills concerned with the items of the INFOLITRANS ${ }^{p}$ questionnaire (Information Literacy for Professional Translators): 


\begin{tabular}{|c|c|c|}
\hline $\begin{array}{c}\text { the transversal instrumental } \\
\text { skills (selection of those } \\
\text { directly related to instruction } \\
\text { in information and } \\
\text { documentation) put forward } \\
\text { by the ANECA report) }\end{array}$ & \\
\hline $\begin{array}{c}\text { Organization and planning } \\
\text { skills (items 7, 17, 19) }\end{array}$ & 3.45 & 3.06 \\
\hline $\begin{array}{c}\text { Capacity for analysis and } \\
\text { synthesis (items 1-5) }\end{array}$ & 3.43 & 3.03 \\
\hline $\begin{array}{c}\text { Computer literacy (items 8, } \\
11,14,15)\end{array}$ & 3.50 & 2.92 \\
\hline $\begin{array}{c}\text { Information management } \\
\text { skills (items 6, 9, 10, 12, 13, } \\
16,18 \text { ) }\end{array}$ & 3.67 & 3.16 \\
\hline Decision making (item 20) & 3.78 & 3.39 \\
\hline
\end{tabular}

Table 2. Descriptive statistics. Cluster skills, ANECA

\begin{tabular}{|c|c|c|}
\hline $\begin{array}{c}\text { INFOLITRANS Cluster } \\
\text { (Following the INFOLITRANS } \\
\text { proposal (Pinto \& Sales, } \\
\text { 2008b) }\end{array}$ & Importance & \\
\hline $\begin{array}{c}\text { Procedural and strategic } \\
\text { competency (items 2, 4, 5, 6, } \\
7,10,14,19,20)\end{array}$ & 3.43 & 2.94 \\
\hline $\begin{array}{c}\text { Information-digital } \\
\text { competency (items 1, 3,8, 9, } \\
11,12,13,16 \text { ) }\end{array}$ & 3.65 & 3.20 \\
\hline $\begin{array}{c}\text { Communication competency } \\
\text { (items 15, 17, 18) }\end{array}$ & 3.45 & 2.99 \\
\hline
\end{tabular}

Table 3. Descriptive statistics. Cluster skills, INFOLITRANS

The ANECA cluster shows that professional translators place greatest importance on the "decision making" item (3.78), which in turn obtains the highest perceived success score (3.39). This comes as no surprise, as the daily experience of professional translators involves a constant round of decision-making in the process of crafting texts and reformulating discourses.

It is noteworthy that the same item, "information management skills", lies in second place for both variables, importance (3.67) and success (3.16). In other words, professional translators understand that managing information flows is both highly relevant and a constant requirement. In third position in terms of importance is "computer literacy" (3.50), 
an increasingly necessary sub-competency in today's ITC environment, followed by "organization and planning skills" (3.45), and "capacity for analysis and synthesis" (3.43). With regard to level of success, "organization and planning skills" (3.06) lies in third place, followed by "capacity for analysis and synthesis" (3.03) and "computer literacy" (2.92), an area in which the surveyed professionals recognize a need for further development.

The INFOLITRANS cluster shows, interestingly, that the results for importance and level of success coincide. For both variables the highest scoring item is information-digital competency (3.65 for importance and 3.20 for success), followed by communicative competency (3.45 for importance and 2.99 for success), while procedural and strategic competency falls in third place (3.43 for importance and 2.94 for success).

By way of summary and before moving on to the descriptive analysis of the open questions, we now present the rankings for both cluster models:

\begin{tabular}{|c|c|}
\hline $\begin{array}{c}\text { Skills needing reinforcement according to the perceptions of translation and } \\
\text { interpretation professionals }\end{array}$ \\
\hline According to the ANECA cluster & $\begin{array}{c}\text { According to the INFOLITRANS } \\
\text { cluster }\end{array}$ \\
\hline Computer literacy & Procedural and strategic competency \\
\hline Capacity for analysis and synthesis & Communicative competency \\
\hline Organization and planning skills & Information-digital competency \\
\hline
\end{tabular}

Table 4. Skills needing reinforcement according to the perceptions of translation and interpretation professionals

These results show that professional translators consider that they need to strengthen their computer-or information-digital-competencies, together with their analytical and synthesizing capabilities (particularly in the case of interpreters, although these are also useful to translators), their organizational, planning, procedural and strategic skills, and their communicative competency. 
We now describe the results deriving from the translators' responses to the open questions designed to provide a close-up view of their needs and perceptions.

\section{Description of the results from the open questions}

We developed a content analysis in order to systematize and organize the relevant information provided by our informants.

21. Briefly, what do you consider to be the main information needs facing the translator in your specialty?

Despite the fact that respondents to the survey work in a range of translation specialties (scientific-technical, literary, audiovisual, legal or administrative, and interpretation), their responses provided a holistic view of the information needs facing translation professionals on a daily basis; we consider the level of representation for a diagnostic study of this type to be particularly enriching, taking into account the scope of the informants' group.

This first, rather generic, open question was designed to identify as broadly as possible the respondents' own perception of their needs. They highlighted the following aspects:

- Verification of sources and/or of information due to problems of noise, particularly in the Internet environment

- Terminological and idiomatic needs that are not met by currently available dictionaries, particularly necessary for minority languages

- Information needs within the specialist field (literature, legal systems, etc.) 
- Needs for cultural information about the contexts of texts to be translated

- Difficulties in accessing experts, personal sources

- Compilation of parallel texts (that means, texts related to the topic of the text one is translating)

These points are relevant from a diagnostic perspective, because, generally speaking, professional translators lack specialized resources of proven quality and assured reliability, at both linguistic-terminological and contextual-cultural levels. At the same time, as the informants declare, there is a clear need to acquire greater competency in managing and retrieving information, especially through information and communication technologies.

In this regard, the critical evaluation of online sources is becoming a need that the body of professional translators perceives as urgent and relevant. Moreover, the deadlines and timings of the translation tasks collide, many times, with the sources available.

22. Do you consider you have the appropriate information competencies to meet these needs? If not, what problems have you come across?

With no doubt, the respondents considered that they have developed competent skills, especially through professional practice, as their experience has grown; however, they highlight the following problems:

- Difficulty in verifying information due to the current plethora of information and poor Internet structure (also mentioned in response to the previous question, showing the relevance the informants give to it)

- Difficulty in areas of creative translation (literary and audiovisual), where needs cannot be foreseen, are constantly changing, and vary greatly 
- Lack of truly specialized reliable resources

- A need to increase the possibility of consulting experts

As can be seen, responses regarding information problems facing translators in their work once again highlighted the variables mentioned in the previous question.

Also of note is the fact that the vast majority of the respondents repeatedly reflect on the impossibility of attaining total information competency, since it must be constantly updated. This is particularly true in any translating specialty. In other words, professional translators are aware that constant updating is necessary to enhance and improve their information competency.

\section{How have you resolved particularly challenging information needs?}

It is highly significant that almost $100 \%$ of the questionnaire respondents reported consulting personal contacts, experts, native speakers, clients, etc. That is, they highlighted direct or personal consultations, or those made through specialist distribution lists.

Secondly, all of them referred to Internet searches and use of electronic resources more than other types of resource. They also pointed to the use of parallel texts and glossaries created previously by themselves or by colleagues. 
Responses to this question largely coincided with the previous question: in the main, expert consultations (direct or via forums) and electronic sources, although in the latter they point to the difficulty of discriminating information and the patience required to locate data; consultation of personal sources therefore is prioritized, firstly because it saves time, and also because it offers a better guarantee of quality and reliability.

Respondents also reported using their own documentation bases, compiled through their professional experience, and specific specialist sources that through continuous use have proven to be of high quality.

25. Have you created your own sources? If so, please describe them.

The types of sources professional translators report having created throughout their professional career include the following:

- Terminological bases and translation memories, almost always using specific software (Microsoft Access, Excel, Multiterm, GesTerm, TRADOS, translation memories in tmx format)

- Glossaries (explanatory-descriptive, with terms in context)

- Compilation of parallel text corpora

- Website lists or lists of personal and institutional contacts

- Concept schemas 
26. As an expert professional, please suggest a specific action you would like to be developed to improve your information competency through self training, or to create sources that would be particularly relevant to your work.

Respondents suggested the following possibilities:

- Forums to encourage communication between colleagues. Specifically, the following ideas were noted:

- Preparation of a directory of translators classified by specialties in order to make contact with expert colleagues

- Creation of a news bulletin on resources, publications, etc.

- Websites or portals containing online resources, specialized according to the needs of each specialist translation area

- Websites with access to specialized glossaries (respondents insisted on the usefulness of sharing resources created through professional practice)

- Basic guidelines to improve information management from the organization and storage perspective; in other words, orientation in information literacy

Our analysis of the questionnaire results concludes with a holistic overview in which we endeavor to correlate the responses to both the closed and the open questions. Professional translators, regardless of their specialty, perceive the need to improve their procedural and strategic competency in the use and management of information, and in a similar vein, in the combination of this competency and computer competency through the use of information and communication technologies, now inseparable traveling companions in the daily task of those who translate. 
However, the critical perspective-indispensable to all translation-is constantly visible; above all, translation professionals express an interest in improving their skills in sifting quality information, and, above all, are requesting improved compilations of qualitative resources arising from practice and experience that should be systematized, ordered and made available to the professional community through websites or content portals.

\section{CONCLUDING REMARKS AND IDEAS FOR FUTURE DEVELOPMENT}

The present paper and the ongoing research project of which it is part are conceived as an applied contribution offered by information studies to a specific community of practice, namely that of translators. In line with our general perspective of action research, we do not make prescriptive proposals from the information studies viewpoint. Rather, our aim is to offer diagnosis and support for the actors of that community of practice, so as to help them pinpoint their authentic needs.

In the light of the results of this study, and although our research remains ongoing, we would like to conclude by offering some proposals for future action, with a view to meeting the needs of professional translators and drawing on their suggestions and perceived needs:

1. External improvement: from a purely cognitive point of view, translators surveyed called for improvements in the quality of available information. Some kind of expert repository consisting of glossaries and material provided by the professional community would significantly contribute to such an improvement.

It should be noted that the best resources are surely those generated by professionals themselves during their professional activity, through arduous searches: 
putting each case in context for each specific need, consulting experts on subjects related to the documentary demands of their assignment, locating and handling dictionaries that are not easily accessed, reading a wide range of specialized material etc.

At the same time, the preparation of specialty-based repositories should also be considered (interpreting for conferences or in public services, scientific-technical translation, audiovisual translation, legal-administrative translation, literary translation), and within these specialties, concrete specializations and needs should be considered by, for example, text genre or subjects. A great deal remains to be done in the creation, organization, optimization and management of expert resources.

2. Internal improvement: from the procedural perspective, translators surveyed recognize their shortfalls and therefore require better training to master information literacy. A series of specialized courses could contribute to resolving these gaps by improving translators' efficiency levels in relation to new technologies.

In this vein, and as a complement to the expert repositories and specialized courses, content portals also provide an important resource as they go beyond information management alone, creating communities of learning and academic spaces that allow a major redefinition of relations between teachers, students, institutions and their outside professional communities.

In other words, it would be adequate and potentially useful to develop online information literacy tutorials (Lindsay, Cummings, Johnson, 2006) specific for this community. This information format can provide structured and relevant content on a variety of IL topics and at a variety of levels. Further, it can provide solutions for issues such as accessibility and timetable flexibility, it can support learners with a range of learning styles, 
and it can enable linking to more advanced or broader layers of content to meet user needs and interests.

\section{REFERENCES}

Andretta, Susie (ed.) (2007) Change and challenge: Information literacy for the 21st Century, Adelaide: Auslib Press.

ANECA (2004) Final Report on the Project for the Design for the Degree in Translation and Interpreting in Spain. URL (consulted December 2009): http://www.aneca.es/activin/docs/libroblanco_traduc_def.pdf

Barnett, R. (1997) Higher Education: A Critical Business, Buckingham: Open University Press.

Bruce, Christine (1997) The Seven Faces of Information Literacy, Adelaide: Auslib.

Bundy, A. (2004) Australian and New Zealand Information Literacy Framework: Principles, Standards and Practice, 2nd edn. Adelaide: Australian and New Zealand Institute for Information Literacy.

Corrall, S. (2007) "Benchmarking strategic engagement with information literacy in higher education: towards a working model", Information Research 12(4), 328. Available at: http://Informationr.net/ir/12-4/paper328.html (accessed 22 Juny 2010).

Hatim, Basil and Mason, Ian (1990) Discourse and the translator. London and New York: Longman.

Journal of Information Literacy (2007) Volume 1. Issue 1. URL (consulted December 2009): http://www.informationliteracy.org.uk/Home/JIL/Vol_1_Issue_1_2007.aspx 
Lindsay, Elizabeth; Cummings, Lara; Johnson, Corey (2006) "If you Build It, Will They Learn? Assessing Online Information Literacy Tutorials." College and Research Libraries 67, 5, $429-45$.

Lloyd, Anne (2006) 'Information Literacy Landscapes: An Emerging Picture', Journal of Documentation 65 (5): 570-83.

Lloyd, Anne and Williamson, Kirsty (2008) "Towards an understanding of information literacy in context: Implications for research". Journal of Librarianship and Information Science, $40(1), 3-12$.

Maughan, D.P. (2001) "Assessing information literacy among undergraduates: a discussion of the literature and the University of California-Berkeley assessment experience." College \& Research Libraries 61(1), 71-85.

Patton, M. G. (1987) Qualitative evaluation methods. Beverly Hills: Sage.

Pinto, María and Sales, Dora (2007) "A research case study for user-centred information literacy instruction: Information behaviour of translation trainees". Journal of Information Science, vol. 33, no. 5, 531-550.

Pinto, María and Sales, Dora (2008a) "Towards User-centred Information Literacy Instruction in Translation: The View of Trainers". The Interpreter and Translator Trainer, 2 (1), 4774.

Pinto, María and Sales, Dora (2008b) "INFOLITRANS: A Model for the Development of Information Competence for Translators". Journal of Documentation, vol 64, n. 3, pp. 413-437.

Pinto, María (2001) "Quality Factors in Documentary Translation". Meta, vol. 46, 2, pp. 288300

Sales, Dora (2008) "Towards a student-centred approach to information literacy learning: A focus group study on the information behaviour of translation and interpreting 
students". Journal of Information Literacy, 2(1). URL (consulted December 2009): http://ojs.lboro.ac.uk/ojs/index.php/JIL/index

Sandberg, J. (2000) "Understanding human competences at work: An interpretative approach." Academy of Management Journal 43(1), 9-17.

UNESCO (2005) Towards knowledge societies. UNESCO World report. Paris: UNESCO.

Zins, C. (2007) "Conceptions of Information Science". Journal of the American Society for Information Science (JASIST), 58 (3), pp. 335-350.

\section{APPENDIX}

SEE SEPARATE FILE 